\title{
Properties of Palm Oil Fuel Ash (POFA) Geopolymer Mortar Cured at Ambient Temperature
}

\author{
Monita Olivia ${ }^{1,2, *}$, Lora Mona Tambunan ${ }^{1}$ and Edy Saputra $^{3}$ \\ ${ }^{1}$ Department of Civil Engineering, Faculty of Engineering, Universitas Riau, Pekanbaru, Riau 28293, \\ Indonesia. \\ ${ }^{2}$ Konsorsium Riset Geopolimer Indonesia (KORIGI), Laboratorium Beton dan Bahan Bangunan \\ Kampus ITS Sukolilo Surabaya 60111, Indonesia. \\ ${ }^{3}$ Department of Chemical Engineering, Faculty of Engineering, Universitas Riau, Pekanbaru, Riau \\ 28293, Indonesia.
}

\begin{abstract}
Geopolymer material needs high temperature curing to produce good microstructure, high strength, and durable product. However, curing at ambient temperature is more preferable and practical in application for cast in situ geopolymer. In order to allow curing at ambient temperature, the geopolymer is mixed with mineral additives that has high calcium content such as slag, Ordinary Portland Cement (OPC) and high calcium fly ash. In this study, the Ordinary Portland Cement (OPC) was added in the Palm Oil Fuel Ash (POFA) geopolymer mortar to induce setting and hardening at ambient temperature. Setting time, compressive strength and porosity of the POFA geopolymer mortar were measured. The OPC was added into the geopolymer at dosages of $0 \%, 20 \%, 25 \%, 30 \%, 35 \%$, and $40 \%$. The alkaline activator used was a combination of $\mathrm{NaOH}(16 \mathrm{M})$ and sodium silicate with a ratio of 2.5 by mass. The POFA geopolymer mortar were cast and cured at ambient temperature. Results show that addition of $35 \%$ OPC increased the setting time by $99.44 \%$, increased the compressive strength of mortar by $95.46 \%$ and decreased the porosity by $5.27 \%$ at 28 days. It can be concluded that inclusion of the OPC could improve the setting and final strength of the geopolymer material.
\end{abstract}

\section{Introduction}

Geopolymer is a binder from material contains silica and alumina and activated by alkaline solution. The geopolymer paste usually needs high temperature curing to accelerate geopolymerization and activate silica to produce strong and dense matrix. Kovalchuck, et al. [1] stated that geopolymer paste hardens very slowly at ambient curing; therefore, this type of concrete is usually subjected to high temperature curing. It was found that high temperature curing in the range of $60-90^{\circ} \mathrm{C}$ is necessary to complete the amorphous aluminosilicate process [2]. Heat will accelerate the reaction in a geopolymer mixture. However, curing of material at high temperature, it is impractical in application since it needs

\footnotetext{
* Corresponding author: monita1306@yahoo.com
} 
special methods or equipments. In this case, geopolymer product is considered costly related due to high temperature curing.

Additives that have high $\mathrm{CaO}$ content such as slag, high calcium fly ash and OPC were reported included to accelerate geopolymer curing at ambient temperature. Slag contains high $\mathrm{CaO}$, hence Deb et al. [3] and Nath and Sarker [4] suggested of using slag to increase reactivity and hydration process, reduce setting time, assist workability and increase early strength properties of geopolymer concrete at ambient temperature. Furthermore, instead of slag, the commercial OPC that contains more $\mathrm{CaO}$ than slag (approximately of $65 \%$ ) was found practical to decrease setting time, and reduce the curing time and temperature. In one study, it was found that the optimum mixture for curing at ambient temperature consisted of $40 \%$ alkaline activator and addition of 5\% OPC to replace fly ash (by total binder) could produce mortar with compressive strength more than $50 \mathrm{MPa}$ [5]. Inclusion of OPC to the mixture was stated could improve setting time, mechanical properties and durability of the fly ash geopolymer [6].

Previous studies about geopolymer material containing Ordinary Portland Cement (OPC) as aluminosilicate source and additive were reported. Initially, the geopolymer was mixed with the OPC to produce OPC-geopolymer composite with stronger properties than the OPC paste alone [7]. In other study, the OPC was added in the geopolymer to produce mortar with the highest strength of $43.1 \mathrm{MPa}$ at room temperature [8]. Approximately $5-12 \%$ of the OPC (by cement weight) was included in the geopolymer paste mixture only to assist the geopolymerization process by generating heat during hydration [9]. The mixtures were also cured at $60^{\circ} \mathrm{C}$ for 24 hours. It was reported that the inclusion of OPC in the mixtures could reduce setting time, porosity and water absorption with the increase of OPC content. There was also improvement in compressive strength and elastic modulus since the OPC could modify the microstructure and pore of the geopolymer paste. Another study that investigate the effect of using OPC in high calcium geopolymer mixture at different curing regime (membrane curing, temperature curing and wet curing) was reported by the same research group. The geopolymer samples cured in tempeture curing $\left(40^{\circ} \mathrm{C}\right.$ for 24 hours) showed better physical properties and high early compressive strength [10].

Utilization of source materials that rich in silica and alumina content has driven usage of agro-industrial biomass such as Palm Oil Fuel Ash (POFA). POFA as geopolymer main source material in Southeast Asia has become popular due to abundant supply from palm oil plantations. POFA is produced from combustion of empty fruit bunch and palm oil kernel. Some studies were carried out to investigate the suitability of POFA as geopolymer's main material and suggested that POFA is a potential source material for the geopolymer due to high silica content $[11,12]$. Furthermore, local POFA from Riau Province could be used to produce gepolymer concrete with compressive strength of $22.58 \mathrm{MPa}$ [13]. Although curing of geopolymers at ambient temperature is important in application, there are still few published studies on POFA geopolymer cured in ambient temperature using the OPC to accelerate curing. The current study aims to investigate the effect of using OPC at various percentage in setting time, compressive strength, and porosity of the POFA geopolymer cured at ambient temperature.

\section{Material and methods}

Palm Oil Fuel Ash (POFA) from Dumai, Riau, was used in this study. Ordinary Portland Cement (OPC) type I was used to accelerate curing at ambient temperature. The chemical composition the Ordinary Portland Cement (OPC) and POFA is presented in Table 1. 
Table 1. Chemical composition of OPC and POFA.

\begin{tabular}{|c|c|c|}
\hline \multirow{2}{*}{ Components } & \multicolumn{2}{|c|}{ Percentage [\%] } \\
\cline { 2 - 3 } & $\begin{array}{c}\text { Ordinary Portland Cement } \\
(\text { OPC)* }\end{array}$ & $\begin{array}{c}\text { Palm Oil Fuel Ash } \\
(\text { POFA) }\end{array}$ \\
\hline $\mathrm{SiO}_{2}$ & 20.92 & 54.53 \\
\hline $\mathrm{Al}_{2} \mathrm{O}_{3}$ & 5.49 & 15.90 \\
\hline $\mathrm{Fe}_{2} \mathrm{O}_{3}$ & 3.78 & 3.86 \\
\hline $\mathrm{MgO}$ & - & 1.21 \\
\hline $\mathrm{CaO}$ & 65.21 & 7.49 \\
\hline $\mathrm{Na}_{2} \mathrm{O}$ & - & 0.09 \\
\hline $\mathrm{K}_{2} \mathrm{O}$ & - & 4.31 \\
\hline $\mathrm{MnO}$ & - & 0.07 \\
\hline $\mathrm{P}_{2} \mathrm{O}_{5}$ & - & 4.90 \\
\hline $\mathrm{SO}_{3}$ & - & 0.87 \\
\hline $\mathrm{Cu}$ & - & 0.02 \\
\hline $\mathrm{Zn}$ & - & 0.01 \\
\hline
\end{tabular}

*Salain 2009, **PSD Geologi Bandung

Alkaline solution used was a combination of sodium silicate $\left(\mathrm{Na}_{2} \mathrm{SiO}_{3}\right)$ and sodium hydroxide $(\mathrm{NaOH}) . \mathrm{NaOH}$ concentration was $16 \mathrm{M}$ and the ratio of $\mathrm{NaOH} /$ sodium silicate used was 2.5. The alkaline activator dosage was based on the recommendations from the previous study [14]. Sodium silicate with a $\mathrm{SiO}_{2} / \mathrm{Na}_{2} \mathrm{O}$ ratio of 2.19 in a $53.7 \%$ liquid and density of 1.56 was mixed with the dissolved sodium hydroxide $\left(\mathrm{Na}_{2} \mathrm{O}\right) 99 \%$ wt. Fine aggregates from Kampar river in saturated surface dry condition with fine modulus of 2.83 and specific gravity of 2.65 were mixed with binders. Superplasticizer contains napthlene sulphonated formaldehyde from Sika was included in the mixture to improve workability. The OPC was included as $0 \%, 20 \%, 25 \%, 30 \%, 35 \%$, and $40 \%$ in the mixtures GP1, GP2, GP3, GP4, GP5 and GP6, respectively.

Table 2. Mixture composition.

\begin{tabular}{|l|c|c|c|c|c|c|c|}
\hline \multirow{2}{*}{ Mixes } & \multicolumn{5}{|c|}{ Quantity $\left[\mathrm{kg} / \mathrm{m}^{3}\right]$} & & \multirow{2}{*}{ w/s } \\
\cline { 2 - 7 } & Sand & POFA & OPC & SS & NaOH & SP & \\
\hline GP1 (OPC0) & 1364 & 495.73 & 0 & 330.49 & 165.24 & 7.44 & 0.57 \\
\hline GP2 (OPC20) & 1364 & 495.73 & 99.15 & 330.49 & 165.24 & 7.44 & 0.57 \\
\hline GP3 (OPC25) & 1364 & 495.73 & 123.93 & 330.49 & 165.24 & 7.44 & 0.57 \\
\hline GP4 (OPC30) & 1364 & 495.73 & 148.72 & 330.49 & 165.24 & 7.44 & 0.57 \\
\hline GP5 (OPC35) & 1364 & 495.73 & 173.51 & 330.49 & 165.24 & 7.44 & 0.57 \\
\hline GP6 (OPC40) & 1364 & 495.73 & 198.29 & 330.49 & 165.24 & 7.44 & 0.57 \\
\hline
\end{tabular}

OPC $=$ OPC Percentage as additive, $\mathrm{R}=$ ratio of $\mathrm{Na}_{2} \mathrm{SiO}_{3} / \mathrm{NaOH}, \mathrm{SS}=$ Sodium Silicate, $\mathrm{SP}=$ superplasticizer, $\mathrm{w} / \mathrm{s}=$ water/solid

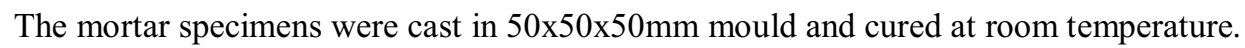
Those specimens were demoulded after 24 hours and placed in the lab until testing date. The measured properties were setting time, compressive strength (at 7 and 28 days), density and porosity. 


\section{Results and discussion}

\subsection{Setting time}

Table 3 shows the initial and final setting times measured for POFA geopolymer mortar at various OPC content. It can be seen that the initial and final setting time of mix GP1 (OPC $0 \%)$ mortar at ambient temperature was much longer than other mixture specimens (GP2-GP6). The POFA geopolymer mixture certainly needs high temperature curing to assist fast geopolymerization process, and curing at ambient temperature delay the paste activation. It can be observed that the setting time for all POFA geopolymer mortars decreased with the increase of the OPC percentage in the mixtures. Both mixes GP5 and GP6 that have shown a rapid increase of setting time than the control mix (GP1). This was confirmed in the previous study that stated fly ash geopolymer mixtures with calcium from the OPC as an additive yielded fast setting concrete [5], which has been also observed for the POFA geopolymer mortar in this research. It was stated that the calcium content is responsible to increase solidification rate and rapid hardening by providing extra nucleation sites for precipitation of dissolved species in geopolymer system [15]. An increase in setting time rate with calcium additive will be beneficial for the POFA geopolymer mortar as repair binding material or plaster in situ.

Table 3. Initial setting and final setting of the geopolymer POFA at different OPC percentages.

\begin{tabular}{|c|c|c|c|}
\hline Mix & OPC Percentages [\%] & Initial setting time [min] & Final setting time [min] \\
\hline GP1 & 0 & 2860 & 3900 \\
\hline GP2 & 20 & 62 & 240 \\
\hline GP3 & 25 & 41 & 135 \\
\hline GP4 & 30 & 24 & 105 \\
\hline GP5 & 35 & 16 & 90 \\
\hline GP6 & 40 & 13 & 75 \\
\hline
\end{tabular}

\subsection{Compressive strength}

Figure 1 shows the compressive strength of POFA geopolymer mortar at various OPC content cured at ambient temperature. At 28 days, the compressive strength of the mortar was in the range 11.73 to $22.93 \mathrm{MPa}$. It can be seen that the compressive strength increased with concrete age for all mixes. A gain in compressive strength of the mortar continued until GP5 (OPC content of 35\%), before it decreased for mix GP6 (OPC content of 40\%). The compressive strength of GP5 has increased by $95.46 \%$ compared to the GP1 (control mix). This could be due to the increase amount of calcium in the geopolymer mixes that form additional Calcium Silicate Hydrate $(\mathrm{CSH})$ in the matrix. The increase percentage of $\mathrm{CaO}$ up to $35 \%$ has altered microstructure of geopolymer gels that could finally enhance the physical, mechanical and properties. The increase in compressive strength was related to the OPC and pozzolanic reactions to form additional $\mathrm{CSH}$ in the matrix $[5,7,9]$. However, when the OPC content was $40 \%$, the compressive strength started to decline. An increase in OPC content enhanced strength development of the geopolymers, but excess calcium caused rapid setting time, and precipitation of aluminosilicate gel altogether with $\mathrm{CSH}$ at the very early stages, resulting in lower strength mortars.

Chemical composition of POFA determine the type of geopolymer product and its interaction with $\mathrm{CaO}$ in the system. For example, POFA used in the previous study by Salih et al. $[16,17]$ consists of $\mathrm{SiO}_{2}, \mathrm{CaO}$ and small content of $\mathrm{Al}_{2} \mathrm{O}_{3}$. Thus, the POFA geopolymer mix produced more $\mathrm{CSH}$ than aluminosilicate product due to higher calcium content than the aluminium content. This low Al content lead to slow setting and low strength development of 
the POFA geopolymer. In this research, the POFA used has relatively higher $\mathrm{Al}_{2} \mathrm{O}_{3}(15.90 \%)$ than $\mathrm{CaO}$ content $(7.90 \%)$. Hence, the aluminosilicate product could be more dominant than the $\mathrm{CSH}$ gels in the geopolymer network. Inclusion of OPC with a reasonably high $\mathrm{CaO}$ content $(65.21 \%)$ in the mix certainly increased $\mathrm{CSH}$ amount, setting and strength development in the POFA geopolymer mortar cured at ambient temperature. This is also probably due to the OPC that generates internal heat inside the specimens. The exothermic heat could enhance further formation of geopolymeric gel and subsequently will improve the mechanical strength of the geopolymers. Similar observation was reported by Moon et al. [18].

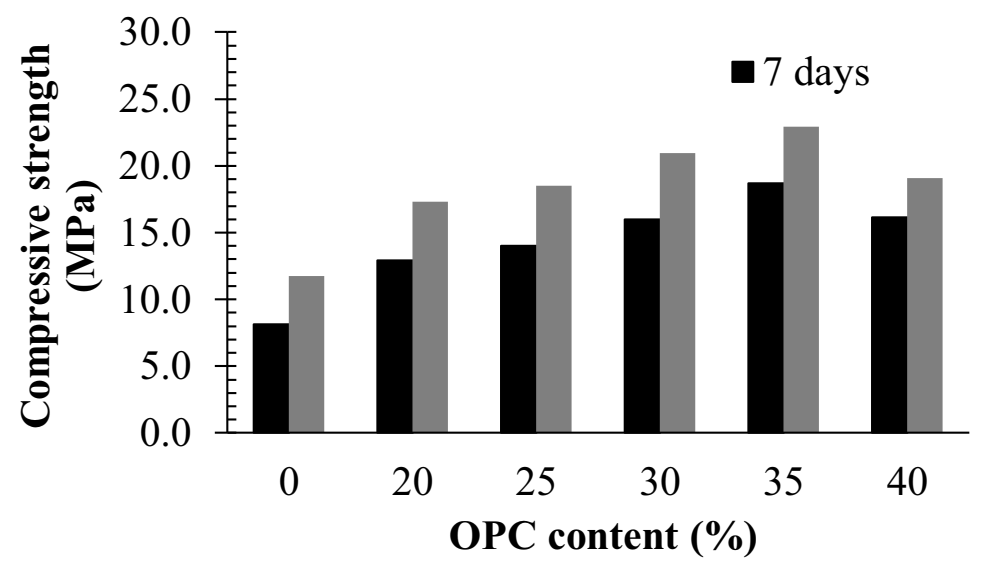

Fig. 1. Compressive strength at 7 and 28 days due to variation of OPC content.

\subsection{Porosity}

Porosity for all mixtures is presented in Figure 2. There was a decline trend of the mortar, showing a slight change in porosity. The porosity values were in the range of $20.73-22.09 \%$. It can be seen that the OPC mortar (control mix GP1) had the highest porosity $(22.09 \%$ ) compared to other geopolymer mixes. The OPC content in the mortar had a good impact for porosity since it increased the calcium content in the geopolymer to produce CSH gels. An increase of calcium content could increase in specimen compressive strength due to increase in the amount of geopolymer product within each sample. On the other hand, the porosities of other mixes were 20-73-21.66\%, respectively. Inclusion of the OPC has definitely increased hydration products and amount of CSH in the mixtures. The CSH products developed and filled the pores and thus reduced the porosity of the mortars, as can be seen for mix GP5 that has shown a decreased in porosity by $5.27 \%$. Pangdaeng et al. [10] reported similar trend for porosity of the fly ash geopolymer mortar using $5-15 \%$ of OPC cured at ambient temperature. It was stated that an extra participation of $\mathrm{CSH}$ from the calcium (OPC) improve the microstructure and decrease porosity, indicating by dense and compact matrix. 


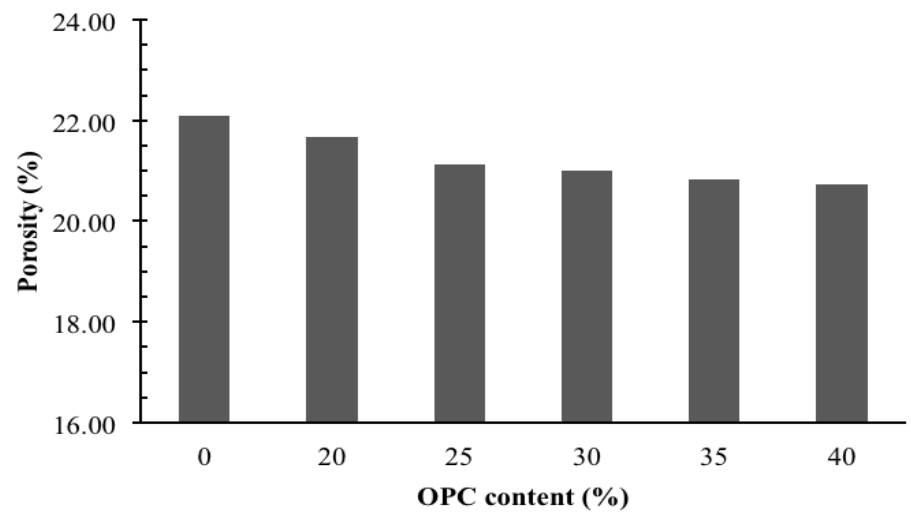

Fig. 2. Porosity at 7 and 28 days due to variation of OPC content.

The effect of inclusion of OPC to assist POFA geopolymer mortar curing at ambient temperature was investigated in this research. Previous study stated that calcium during geopolymerization had two roles [6]. The first role is to aid aluminosilicate dissolution from fly ash particles. The second role of calcium is as counter-balancing cation in the geopolymer pore structure by incorporating calcium in the geopolymer network system. Another role of calcium in the geopolymer mix was observed to increase internal heat from the exthermic reaction of OPC hydration that could assist ambient curing condition [19]. In this research, the optimum combination obtained was using $\mathrm{NaOH} 16 \mathrm{M}$ concentration, ratio of $\mathrm{NaOH} / \mathrm{Na}_{2} \mathrm{SiO}_{3}$ of 2.5 , using $35 \%$ OPC as additive that will produce mortar with compressive strength of $22.93 \mathrm{MPa}$ and porosity of $20.82 \%$. It can be summarized that inclusion of the OPC could improve the setting, final strength and porosity of the POFA geopolymer mortar.

\section{Conclusions}

The present study investigated the use of various percentage of OPC in POFA geopolymer for curing at ambient temperature. The OPC mortars (GP1) was used as control specimens. It could be seen that there was a decrease in setting time, an increase in compressive strength and a decrease in porosity of POFA geopolymer at 7 and 28 days. The OPC addition in the geopolymer system increased the calcium content in the mixture and produced Calcium Silicate Hydrate $(\mathrm{CSH})$. The additional $\mathrm{CSH}$ improved mictrostructure and strength development of the geopolymer. In this research, the optimum combination obtained was using $\mathrm{NaOH} 16 \mathrm{M}$ concentration, ratio of $\mathrm{NaOH} / \mathrm{Na}_{2} \mathrm{SiO}_{3}$ of 2.5 , using $35 \%$ OPC as additive that will produce mortar with compressive strength of $22.93 \mathrm{MPa}$ and porosity of $20.82 \%$. It can be summarized that the OPC inclusion will improve setting, final strength and porosity of the POFA geopolymer mortar.

The authors would like to acknowledge the Geopolymer Research Group Universitas Riau, all member of Final Year Project Group Batch 2 and 3, and the Structural Engineering and Concrete Laboratories, Faculty of Engineering, Universitas Riau. 


\section{References}

1. G. Kovalchuck, A. Fernandez Jimenez, A. Palomo, Fuel, 86, 315 (2007)

2. D. Hardjito, S.E. Wallah, D.M.J. Sumajouw, V. Rangan, ACI Mater. J., 101, 467 (2004)

3. P.S. Deb, P. Nath, P.K. Sarker, Mater. Des., 62, 32 (2014)

4. P. Nath, P.K. Sarker, Constr. Build. Mater., 66, 163 (2014)

5. P. Nath, P.K. Sarker, Cem. Concr. Compos., 55, 205 (2015)

6. G.M. Canfield, J. Eichler, K. Griffith, J.D. Hearn, J. Mater. Sci., 49, 5922 (4014)

7. J. Tailby, K.J.D. MacKenzie, Cem. Concr. Res., 40, 787 (2010)

8. A. Nazari, H. Khammohammadi, M. Amini, H. Hajiallahyari, A. Rahimi, Mater. Des., 41, 43 (2012)

9. T. Phoo ngernkham, P. Chindaprasirt, V. Sata, S. Pangdaeng, T. Sinsiri, Int. J. Min. Met. Mater., 20, 214 (2013)

10. S. Pangdaeng, T. Phoo ngernkham, V. Sata, P. Chindaprasirt, Mater. Des., 53, 269 (2014)

11. M.A. Salih, A.A.A. Ali, N. Farzadnia, Constr. Build. Mater., 64, 591 (2014)

12. M.J.A. Mijarsh, M.A.M. Johari, Z.A. Ahmad, Constr. Build. Mater., 52, 473 (2014)

13. M. Olivia, A. Kamaldi, I.R. Sitompul, I. Diyanto, E. Saputra, Mater. Sci. Forum, 803, $110(2015)$

14. D. Hardjito, S.E. Wallah, D.M.J. Sumajouw, B.V. Rangan, ACI Mater. J., 101, 467 (2004)

15. W.K.W. Lee, J.S.J. van Deventer, Colloids Surf., A 211, 115 (2002)

16. M.A. Salih, A.A.A. Ali, N. Farzadnia, Constr. Build. Mater., 65, 592 (2014)

17. M.A. Salih, N. Farzadnia, A.A.A. Ali, R. Demirboga, Constr. Build. Mater., 93, 289 (2015)

18. J. Moon, S. Bae, K. Celik, S. Yoon, K. Kim, K.S. Kim, P.J.M. Monteiro, Cem. Concr. Compos., 53, 2118 (2014)

19. T. Suwan, M. Fan, N. Braimah, Constr. Build. Mater., 114, 297 (2016) 